\title{
Current concept of the pathogenesis of peri-implantitis and the role of bactéria.
}

Anthony Davis (1) and Mary Davis

\section{ARTIGO ORIGINAL}

Abstract

Through an extensive review of the literature, our objective will be to clarify the current concept that exists about the pathogenesis of peri-implantitis, as well as the implications that bacteria may have on it. To date, different longitudinal and cross-sectional studies have identified some of the risk factors or risk indicators of peri-implantitis. Previous history of periodontal disease, diabetes, genetic load, poor oral hygiene, tobacco, alcohol consumption, absence of keratinized gingiva and the surface of the implants are some of the factors that have been analyzed in detail in the literature. The colonization of new surgically implanted surfaces represents a risk situation in partially edentulous patients, where periodontopathogenic bacteria from the residual bag play an important role.

Key words: Peri-implantitis, pathogenesis and risk factors. 


\section{Conceito atual da patogênese da peri-implantite e o papel das bactérias.}

\section{Resumo}

Por meio de uma extensa revisão da literatura, nosso objetivo será esclarecer o conceito atual existente sobre a patogênese da peri-implantite, bem como as implicações que as bactérias podem ter sobre ela. Até o momento, diferentes estudos longitudinais e transversais identificaram alguns dos fatores de risco ou indicadores de risco de peri-implantite. História pregressa de doença periodontal, diabetes, carga genética, higiene bucal precária, tabagismo, consumo de álcool, ausência de gengiva queratinizada e superfície dos implantes são alguns dos fatores detalhadamente analisados na literatura. A colonização de novas superfícies implantadas cirurgicamente representa uma situação de risco em pacientes parcialmente desdentados, onde bactérias periodontopatogênicas da bolsa residual desempenham um papel importante.

Palavras-chave: Peri-implantite, patogênese e fatores de risco.

Instituição afiliada: 1- Professor Emeritus of the Faculty of Dentistry of Guiane.

Dados da publicação: Artigo recebido em 10 de maio, revisado em 15 de maio, aceito para

publicação em 20 de maio e publicado em 30 de maio.

DOI: https://doi.org/10.36557/2674-8169.2021v3n5p09-30

Anthony Davis adavidentistry@gmail.com

\section{(i)}

This work is licensed under a Creative Commons Attribution 4.0 International

License. 


\section{INTRODUÇÃO}

In the origin and development of peri-implantitis, it is important to consider 3 groups of factors: those related to the ability to colonize the implant surface, the composition of the peri-implant flora, and the host's susceptibility to infection.

When it comes to replacing a lost tooth, there are different treatment alternatives. Since the mid-1960s, thanks to Professor Bränemark, we have had dental implants among other treatment alternatives that allow us to offer patients the best solution to this situation. This treatment alternative has continued to be extensively investigated to date in order to know its stability and survival, thus allowing it to be today the most experienced treatment option in most situations in which tooth replacement is required.

In the last 20 years, dental implants and implant-supported frameworks have become the most common treatment choice over conventional removable and fixed partial dentures, which has inevitably caused that as the number increases of patients receiving this type of treatment, the incidence of peri-implant infections increases.

Despite the high survival rate of implants reported in 10-year follow-up studies, peri-implant mucositis and peri-implantitis are frequently found around implants.

The concept of peri-implantitis was introduced at the end of the 1980s to describe those situations of inflammatory process and destruction that take place in osseointegrated tissues, giving rise to the formation of the peri-implant pocket and marginal bone loss. This disease can affect only the peri-implant mucosa (mucositis) or include the involvement of the supporting bone (peri-implantitis). In the consensus of the first European Workshop on Periodontology the term "peri-implantitis" was defined as a clinical diagnosis that requires evaluation of inflammation of the peri-implant tissues as well as loss of supporting bone (Albrektsson and Isidor 1994).

The objective of this review will be to clarify the current concept that exists about the pathogenesis of peri-implantitis, as well as the implications that bacteria may have on it.

\section{Peri-implantitis Pathogenesis}

Biological complications occur around implants, described according to Berglundh et al. As "interruptions in implant function characterized by a biological process that affects the hard and soft tissues that support the implant."(Berglundh et al. 2002). Mucositis, described as an inflammatory lesion in which the cells of the inflammatory 
tissue themselves infiltrate the connective tissue, is considered a clinical manifestation in which said inflammatory changes are restricted to the mucosa However, if the lesion progresses, affecting the tissues around the osseointegrated implants, showing inflammation of the peri-implant mucosa and clinical and radiographic bone loss $=3$ turns comparing the radiographs taken in the examination. baseline and 1 year later after implant placement, it would be peri-implantitis.

Other clinical signs of the disease may include: redness and hyperplasia of the periimplant mucosa, exudate, suppuration, bleeding on probing, increased probing depth, recession, pain on percussion, and progressive implant mobility (in more advanced cases). It is important to make a good diagnosis, since if the peri-implant lesion is not diagnosed in time it will lead to a complete loss of the implant (Berglundh et al. 2002, RoosJansa ${ }^{\text {or }}$ ker et al. 2006, Heitz-Mayfield 2008).

Regarding the factors related to the origin and development of peri-implant disease, it is important to consider those related to the ability to colonize the implant surface. This first factor must be especially taken into account when selecting the surface that we believe is most appropriate for the implant, since the factors that favor osseointegration in turn increase the probability of biofilm formation. In the same way, general factors related to periodontal disease such as poor oral hygiene and tobacco, as well as specific factors: immunosuppression by drugs and the human immunodeficiency virus (HIV), increase the risk of peri-implantitis (Ong and cols. 2008).

To identify true risk factors, prospective longitudinal studies are needed; however, the difficulty of conducting this type of long-term studies makes us use retrospective and cross-sectional studies, which help us to determine the risk indicators of the disease. Previous history of periodontal disease, diabetes, genetic load, poor oral hygiene, tobacco, alcohol consumption, absence of keratinized gingiva and the surface of the implants are some of the factors that have been analyzed in detail in the literature and on which we will deal with decipher the existence or not of the risk they pose for periimplant disease.

\section{Previous history of periodontal disease}

Once the planned periodontal treatment has been completed according to the patient's needs (oral hygiene instructions, elimination of factors related to the etiology of the disease, receiving: scaling and root planing, periodontal surgery, periodontal regeneration and implant placement), the maintenance program must be strictly complied with by the patient since they have a high susceptibility to disease recurrence. For this reason, adequate oral hygiene and maintenance periodontal therapy must be rigorously carried out by the patient and the professional (Nyman et al. 1977, Axelsson \& Lindhe 1981). 
In the literature, it has been widely debated whether partially edentulous subjects with a previous history of periodontal disease and who have been treated periodontally are exposed to a greater risk of developing peri-implantitis after receiving implant treatment, the implant surface being colonized by bacteria present in remaining teeth, considering that infectious etiology and host response play the same role in predisposition to disease (Quirynen et al. 2002). This is especially important for long-term forecasting (De Boever \& De Boever 2006). Despite the possible existence of a higher risk, the involvement of the periodontal patient can be reduced with the help of maintenance therapy and implants of minimal or moderate roughness (Quirynen et al. 2007).

Some studies report a significantly higher incidence of peri-implant disease and implant loss in this type of patient than in periodontally healthy individuals (Karoussis et al. 2007, Roos-Jansa ${ }^{\circ}$ ker et al. 2006). Schou et al. In 2006, they concluded in their review that the survival of suprastructures and implants does not depend on periodontal status, although a significant increase in the incidence of peri-implantitis and marginal bone loss around the implant is shown in subjects with tooth loss associated with periodontal disease. On the other hand, Serino et al. showed that peri-implantitis was a common finding in patients with mild signs of bone loss in the remaining natural dentition but without signs of periodontitis (considering the presence of a periodontal pocket with a probing depth greater than or equal to $6 \mathrm{~mm}$,) due to the correct hygiene that patients could achieve in the natural dentition and the difficulty of it in implants (Serino et al 2009).

It still seems to be not entirely clear and therefore it is difficult to draw solid conclusions. Despite the limitations that we can find in the literature, recent systematic reviews have concluded that subjects with a history of periodontal disease may be exposed to a greater risk of infections, complications and future implant loss, with special emphasis on the fact that the data that support this conclusion are not very strong (HeitzMayfield. 2008, Ong et al. 2008, Renvent et al. 2009). The latest data in this regard collected in a systematic review indicate that implant survival in patients with a previous history of treated periodontal disease ranges from 59-100\% (Mayfield 2009 a). However Klokkevold \&Hand in another systematic review comparing the results of implants in patients treated for periodontal disease and non-periodontal patients, did not find statistically significant differences in implant survival after performing a meta-analysis of 3 cohort studies concluding that the history of periodontal disease does not seem an adverse effect on implant survival but that these types of patients may experience a greater number of complications and a lower rate of success, especially in the long term (Klokkevold \& Hand 2007)did not find statistically significant differences in implant survival after performing a meta-analysis of 3 cohort studies, concluding that the history of periodontal disease does not appear to have an adverse effect on implant survival but that these types of patients may experience a greater number of complications and a lower range of success, especially in the long term (Klokkevold \& Hand 2007)did not find statistically significant differences in implant survival after performing a meta-analysis of 
3 cohort studies, concluding that the history of periodontal disease does not appear to have an adverse effect on implant survival but that these types of patients may experience a greater number of complications and a lower range of success, especially in the long term (Klokkevold \& Hand 2007)

The effect of tobacco in patients with a history of treated periodontal disease has been evaluated by a large number of studies. Mayfield in his latest systematic review provides us with implant failure rates in this type of patient according to different authors, ranging from 2.6 to 3.1 (Mayfield 2009 a). In patients treated for periodontal disease Jansson et al. observed significantly more early implant failures in smoking patients compared to non-smoking patients (Jansson et al. 2005).

\section{Diabetes}

Diabetes is a complex disease with different oral and systemic complications that depend on metabolic control, the presence of infection, and demographic variables. The importance of glycemic control for the prevention of complications of the disease is well known.

Attachment loss is a frequently encountered clinical sign in this type of patient (Westfelt et al. 1996), being more advanced in subjects with severe systemic complications. Starting from a strong association established between periodontal disease and diabetes, and the possible relationship between the history of periodontal disease and peri-implantitis, it seems logical to ask whether there is an association between peri-implantitis and diabetes. This association has been described in a crosssectional study which analyzes the risk variables related to an increase in the odds ratio of suffering from peri-implantitis, such as: gender, plaque levels (PI) and bleeding on probing (SS).In their results, they observed that the presence of periodontitis and diabetes were shown to be significantly associated with an increased risk of having peri-implantitis, revealing the existence of a relationship between diabetes with poor metabolic control and peri-implant lesions (Ferreira et al. 2006). Previous studies have suggested that poorly controlled diabetes is responsible for a delay in the healing process, increasing susceptibility to infection or future implant loss (Fiorellini \& Nevins 2000).increasing susceptibility to infection or future implant loss (Fiorellini \& Nevins 2000).increasing susceptibility to infection or future implant loss (Fiorellini \& Nevins 2000).

\section{Genetics}

The identification of genetic polymorphisms as risk indicators of peri-implantitis have been extensively investigated without reaching congruent conclusions.

The polymorphism of interleukin 1 (IL-1) is the most investigated to date since said interleukin plays a fundamental role in the regulation of the inflammatory response. However, no association has been found between IL-1 genotype and implant failure or 
bone loss (Jansson et al. 2005), as well as with peri-implantitis (Lachmann et al. 2007). Assuming that the polymorphism of the gene poses a risk for periodontal disease, the same does not happen with peri-implantitis, so this effect should not be attributed to the risk of peri-implantitis. On the contrary, a recent study that has investigated the polymorphism of the IL-1 gene in patients with peri-implantitis suggests a significant association between the two (Laine et al. 2006).

On the other hand, different studies in turn consider the effect of tobacco consumption and the existence of a possible interaction with the polymorphism of the IL1 gene, peri-implant bone loss and inflammation of the peri-implant mucosa. The results show a significant synergistic effect of tobacco use and the polymorphism of the IL-1 gene that results in an increased risk of peri-implant bone loss (Feloutzis et al. 2003). Similarly, an association has been observed between positive heavy smokers for the IL-1 genotype polymorphism and peri-implantitis (Gruica et al. 2004), and future prospective studies with larger sample sizes are necessary to confirm this association and establish more solid conclusions.

\section{Poor Oral Hygiene}

Just as calculus is the main etiological factor of periodontal disease, favoring bacterial accumulation thanks to its porous and retentive surface and making it difficult to control the patient's plaque, it is extremely important to prevent its formation with strict oral hygiene measures together with its removal to achieve adequate periodontal therapy. This rapid biofilm formation capacity occurs both in natural dentition and on artificial surfaces exposed to the oral cavity, on which similar microbiological deposits have been described according to different longitudinal and cross-sectional studies.

Ferreira et al. establish a strong association between poor oral hygiene and periimplantitis with OR = 14.3; and a 95\% confidence interval, said association being dose dependent (Ferreira et al. 2006).

Some local factors such as good accessibility to facilitate hygiene in the implant location seem to be related to the presence or absence of peri-implantitis. In agreement with this statement, Serino et al. in 2009 , they pointed out in their study the association found between peri-implant lesions and inadequate accessibility / capacity since it allowed the patient to carry out hygiene measures in the locations where the implants were located ( $48 \%$ of the implants with peri-implantitis did not show correct access for good plaque control), while in those locations where there was good plaque control, it was not frequent to find affected locations (only $4 \%$ of the implants with good access for plaque control showed peri-implantitis).

In this way, local factors can play a role in the development of peri-implantitis, and it is essential to emphasize the importance of providing adequate hygiene measures to 
patients with cleaning difficulties in prosthetic implant restorations.

\section{Tobacco}

Tobacco is a common habit in the young and middle-aged population of many countries, and its effect on the immune system and health has been extensively investigated. In 1947 Pindborg was one of the first researchers to study the association between smoking and periodontal disease, observing a higher prevalence of periodontal disease in subjects with this habit.

There is scientific evidence that tobacco use is a risk factor for the progression of periodontal disease (Bergstrom 1989, Mayfield 2005) and its effect on: the biofilm (bacteria), the host response and its healing and response to periodontal treatment. These associations have motivated the investigation of future studies on the possible relationship between tobacco and peri-implantitis.

Subsequently, numerous studies have confirmed this fact, showing this association and describing tobacco as a risk factor for mucositis (Attard \& Zarb 2002) and peri-implantitis (Baelum \& Ellegard 2004, Gruica et al. 2004, Roos-Jansa ${ }^{\circ}$ ker and cols. 2006).

The tissue effects of tobacco include: delayed healing, reduced collagen synthesis, impaired fibroblast function, reduced peripheral circulation, and compromised neutrophil and macrophage function (Palmer et al. 2005 ). As well as the negative effect of tobacco on the outcome of periodontal treatment has also been demonstrated (Mayfield 2009 a).

Bain \& Moy in 1993 analyzed its effect on the proportion of failed implants (implant loss or bone loss $>50 \%$ of the implant length), conducting a study comparing implant placement in smokers and non-smokers, resulting in patients smokers a significantly higher percentage of failures ( $11.28 \%$ smokers versus $4.76 \%$ non-smokers), and therefore concluding that smoking is an important factor to consider in implant failure as well as for the development of the inflammatory process and deep pockets around the implant (Baig \& Rajan 2007, Espósito et al. 1998). Being greater in the maxilla than in the mandible, in agreement with other authors (Espósito et al. 1998).

Despite the inconsistency of the definition of smoker between the studies, a large number of studies assess the effect of the dose of smoking tobacco. Regarding the amounts of tobacco consumed, Schwartz-Arad et al. classified their sample of patients into two groups according to the number of cigarettes consumed per day (average smokers: $=10$ cigarettes / day, heavy smoker: $=10$ cigarettes $/$ day) and according to the duration of the habit (average smokers $=10$ years, heavy smokers : $=10$ years) (SchwartzArad et al. 2002). Both groups were shown to have significantly more complications than non-smoking patients, as the number of complications increased as the time of consumption increased. The long-term effect of tobacco significantly increases the risk of 
implant failure from 1,5 in patients who have smoked for less than 10 years to 5.36 in patients who have been smokers for more than 40 years (Mundt et al. 2006).

Lindquist et al. observed differences according to the amount of tobacco consumed, where habitual smokers showed a higher proportion of implant failure, establishing a positive correlation between the increase in tobacco consumption and the increase in the percentage of implant failures. (Lindquist et al. 96, De Luca 2006, Alsaadi et al. 2007). Sánchez-Pérez et al. observed a risk of implant failure of $15.8 \%$ with an odss ratio of 13.1 in smokers, a 10\% relative risk of implant loss in light and moderate smokers ( $<10$ cigarettes / day and 10-20 cigarettes / day). day respectively) being up to $30.8 \%$ in chain smokers ( $>20$ cigarettes / day) (Sánchez-Pérez et al. 2007).A history of smoking in which individuals smoke more than 25 packs per year has been shown to be a significant factor for late implant loss with an odds ratio of 2.01 (De Luca 2006).

On the contrary, Tabanella et al. in 2009 they show in their study that the level of tobacco consumption is not significantly associated with peri-implant bone loss. However, recent studies indicate a dose-dependent effect between the duration of the habit and the proportion of implant failure due to possible irreversible damage (Mundt et al. 2006).

In order to clarify some doubts, Bain \& Moy in 1996 formulated a protocol for smoking cessation that has been subsequently used in different studies, where patients who continue with the habit and those who follow said protocol are compared. In the study results, they found statistically significant differences in implant failure between both groups, where those patients who gave up the habit showed a tendency to reduce the adverse effects of tobacco on the proportion of implants with failure. Some authors even suggest that the risk of complications in an ex-smoker may be reduced to the same in a non-smoker with the cessation of the habit (Shwartz-Arad et al. 2002).

Implant survival can be described in different ways depending on the study. Some studies report implant survival data from the moment of implant placement, while other studies do so from the moment of implant loading. Some studies even differentiate the time of implant loss categorized as early or late loss.

In most cases, implant failure occurs during the second phase (failure to maintain osseointegration after loading) rather than involvement of the osseointegration phase, observing a failure rate in smokers of more than double compared to non-smoking subjects (Baig \& Rajan 2007).

A recent systematic review in which 88 publications were included that analyzed the risk of tobacco on implants, 3 of the 4 systematic reviews included considered tobacco as a significant risk for adverse implant outcomes. While most studies report high implant survival rates in smokers ranging from 80 to $96 \%$, most of them agree that these are lower 
in smokers than in nonsmokers (Mayfield 2009 a).

In cohort studies looking at subgroups of smokers and nonsmokers reviewed in a systematic review (Mayfield 2009):

Of the 59 studies that looked at implant survival, the vast majority agree on significantly longer survival for implants placed in nonsmoking patients. Only 17 studies do not find significant differences between the two categories.

In smoking patients, they found a range of implant survival from 80 to $96 \%$ and an odss ratio for failure of 2.03 to 6.89 .

All the studies they reviewed except one indicate that smoking is detrimental to the success and survival of implants placed with sinus lift.

Despite the fact that most of the literature affirms that tobacco is a significant risk factor for implant failure, there are certain opinions that do not support this theory, not finding such differences between smoking and non-smoking patients regarding the influence of tobacco on implant failure (Bain et al. 2002). Interestingly, in another study, peri-implantitis was a more frequent finding in non-smoking subjects than in smokers, occurring similarly in subjects without periodontitis (Serino 2009). Although some limitations must be taken into account, such as the small sample of smokers used in the study, which prevent us from establishing firm conclusions.

Weyant \& Burt in 1993 and Weyant in 1994 reported on data obtained from 598 subjects and 2,098 controlled implants over a five-year period in which they observed a failure of approximately $4 \%$ of the implants placed. Risk factors found for implant loss included plaque, smoking, and other local factors. Other complications related to implant failure in smoking patients have been analyzed such as marginal bone loss and adverse effects on bone grafts (Feloutzis et al. 2003, Chung et al. 2007).

Taking into account that smoking is not an absolute contraindication for implant placement and the implant survival rate that is described in most of the literature is $80 \%$ $-96 \%$, smoking patients should be informed that there is an increased risk of periimplantitis and future implant loss (the odds ratio of peri-implantitis shown by studies ranges from 3.6 to 4.6). Furthermore, the combination of treated periodontal disease and tobacco use increases the risk of implant failure and peri-implant bone loss (Mayfield et al. 2009 a).

\section{Alcohol consumption}

The literature that we can find in this regard is not very extensive. Only one prospective study points to alcohol as a risk indicator for peri-implantitis, showing a marginal bone loss significantly related to daily alcohol consumption (of $410 \mathrm{~g}$ ), this loss 
being greater than that induced by tobacco consumption (Galindo-Moreno et al. 2005). However, more research is needed to support these claims.

\section{Keratinized tissue}

There is another factor in relation to the health of the peri-implant soft tissues that can influence the response of the tissues to aggression, be it traumatic (friction of a prosthesis, poor fit ...) or infectious. Whether or not an inserted keratinized gum band surrounds the teeth has been a great topic of debate.

It is well known that this gingiva band is not essential to establish periodontal health, but we may wonder if the same thing happens to preserve or maintain the health of the peri-implant tissues. It has been described in the literature that there is a greater susceptibility to the progression of peri-implantitis in implants that are surrounded by mobile, non-keratinized alveolar mucosa (Warrer et al. 1995). However, there are no clinical studies that support the idea that the absence of keratinized gingiva or its width significantly influences plaque control, bleeding index or probing depth, not being an essential requirement for the maintenance of gingival health, which may lead to increased frequency and progression of peri-implantitis (Wennstrom et al. 1994).

On the other hand, clinical experience shows us that the presence of an inserted keratinized gingiva band offers greater resistance, avoiding or delaying the loss of seal around the implants and thus avoiding the invasion and bacterial colonization of the periimplant groove (García-Calderón et al. 2004).

\section{Implant surface characteristics}

There are a great variety of characteristics regarding the topography, roughness and chemical composition of the implant surface. The design of implants has changed a lot since the beginning, today most implants on the market have moderately rough surfaces, since they have shown an improved bone response compared to that shown by very rough or smooth surfaces. (Albrektsson \& Wennerberg 2004).

The characteristics of the implant surfaces, their roughness and the energy-free surfaces are a key factor for bacterial adhesion, serving the implant as a basis for the establishment and growth of the biofilm in the oral ecosystem. This situation can be improved by reducing the roughness of the surface, making it difficult to accumulate plaque that prevents or reduces bacterial adhesion. Studies comparing different types of surfaces from smooth, rough and moderately rough affirm that both bacterial adhesion (Wu-Yuan et al. 95), as well as marginal bone loss (Baelum \& Ellegaard 2004) and the consequent appearance of peri-implant lesions are more common on rough implant surfaces (Astrand et al. 2004). Most of the studies analyzed in a recent review coincide in observing survival rates of implants with moderately rough surfaces greater than $90 \%$ (Mayfield 2009 a). 
An in vitro study with the objective of evaluating the roughness of titanium surfaces necessary to reduce colonization after 24 hours of exposure to the oral environment, have shown in its results that an average roughness of a titanium surface $\geq 0.088 \mu \mathrm{m}$ and $\leq 1,027 \mu \mathrm{m}$ greatly inhibited plaque accumulation and maturation after this period (Rimondini et al. 1997, Subramani et al. 2009).

Biofilm formation is influenced not only by the characteristics and roughness of the implant, but also by the chemical treatment and its energy-free surfaces in the implant material (Karthikey et al. 2009). Modification of implant surfaces with titanium nitrite ( TiN) or zirconium nitrite ( $\mathrm{ZrN}$ ) treatments by thermal oxidation and laser radiation have shown significantly less bacterial adhesion compared to machined implant surfaces in in vitro and in vitro studies. live (Grössner et al. 2001, Scarano et al. 2003). Pure metals, especially titanium, nickel, steel and vanadium contain a bacteriostatic effect that allows them to inhibit bacterial growth, with titanium ranking second after gold (Berry et al. 1992).However, there are in vivo and in vitro studies that deny the significant bacteriostatic role of this metal (Leonhardt et al. 1995, Leonhardt et al. 1995).

The existence of a defect in the junction between the implant and the abutment is one of the main reasons for peri-implantitis (Quirynen et al. 1994). This microscopic bond between implant and abutment, abutment material, over-contoured restorations, and the characteristics or properties of the abutment and implant play a crucial role in bacterial colonization, so it is especially important to develop surfaces that minimize adhesion of primary colonization. .

\section{What is the role of bacteria in the pathogenesis of Peri-implantitis?}

The peri-implant flora, the formation of biofilm on the implant surfaces and the accumulation of plaque that occurs when there are poor oral hygiene conditions are the factors that play a major role in the etiology of the disease. The biofilm comprises a long complex of bacterial species present both on dental and implant surfaces, following a specific pattern with the ability of initial colonizers to adhere to the film and followed by secondary colonizers through interbacterial adhesion (Rosan \& Lamont 2000).

\section{Colonization pattern in natural teeth and implants}

The formation of bacterial plaque in the natural dentition is the main source of colonization of the newly implanted surfaces in partially edentulous subjects. Some studies show an early colonization of these surfaces by periodontopathogenic bacteria in these types of patients (Mombelli et al. 1988; van Winkelhoff et al. 2000).

This colonization process of the periodontopathogenic bacteria that occupy the residual pocket are established on the new inserted surfaces, as revealed by the samples taken from the peri-implant groove of the implants after a few weeks. However, the development of peri-implant mucositis will need more time for its appearance in the first 
6 months. (From Boever \& De Boever 2006).

More recently, the presence of bacteria has been confirmed in fluid samples taken from the peri-implant and gingival sulcus approximately 30 minutes after the completion of implant placement (Furst et al. 2007). This same study concludes that the rapid establishment of the microbiota that occurs after the surgical procedure in the placement of implants does not differ from that that occurs in natural neighboring teeth. Bacteria such as Fusobacterium and Porphyromonas gingivalisthey have been implicated as main pathogens in periodontal disease and at the same time isolated in peri-implant disease (Rutar et al. 2001). This fact may be supported by what some authors suggest, who explain that implant colonization 25 days after second-phase surgery depends on the microbiota of the adjacent dentition (Callan et al. 2005, De Boever \& De Boever 2006).

Another recent study whose objective was to evaluate the early colonization pattern of the locations with implants and locations of adjacent teeth at the time of placement, at 12 weeks and 12 months, shows only small differences in the prevalence of bacterial species detected in both locations at 12 months (Salvi et al. 2008).

Other parts of the oral cavity such as the tongue, tonsils, or oral mucosa can also act as a reservoir of periodontopathogenic bacteria for peri-implant colonization. In a very current study, peri-implant lesions with high levels of periodontopathogenic bacteria have been observed in patients who have remained edentulous for 8 months prior to implant placement (Emrani et al. 2009).

\section{Peri-implant microflora}

The Actinomyces and $V$. parvula species found in the gingival fluid of natural teeth and implants have been described as early colonizers (Socransky \& Haffajee 2005), and later, the Streptococci species especially S. gordonii co-adheres with P. gingivalis.

Van Winkelhoff et al. in 2000 they describe a submucosal microbiota in which Peptostreptococcus micros, Fusobacterium nucleatum and Prevotella intermedia predominate as early colonizers. Thus, the inflammatory response observed in mucositis and peri-implantitis may depend on specific pathogens that exhibit affinity for titanium and on host-related interactions, thus explaining the specific inflammatory response of peri-implant lesions. Some of these species such as $P$. gingivalis and Prevotella intermedia have the ability to have a high affinity for titanium, which facilitates the formation of biofilm (Fürst et al. 2007). Another example is that of $S$. aureus autolysin which has been described as an important early colonizer of titanium implants (Costerton et al. 2005).

It has even been suggested that there may be the possibility of predicting the detection or lack of detection of the species of $S$. aureus at one year based on the 
respective data at 12 weeks, based on the thought that this particular microorganism is associated with peri-implantitis. .

In addition to the material from which the implant is made, the characteristics of its surface have an important implication in the adhesion potential that the bacteria and the host cells possess, contributing to the early colonization of the implant (van Winkelhoff et al. 2000). The existence of this probable association between implant design and the composition of the peri-implant microflora needs to be investigated in more detail.

Another possible relationship between peri-implant flora and implant status has also been established. In those cases in which the implant is stable, it seems common to find gram-positive cocci and gram-negative rods, with an increase in the count of gram-negative anaerobic bacilliand a decrease in the proportion of grampositive cocci in mucositis. As the disease progresses, the microflora also continues to change its composition but in a more significant way compared to a healthy tooth, detecting in this case: Porphyronomas gingivalis, and in some rare cases Aggregatibacter actinomycetemcomitans. Porphyronomas gingivalisit is an anaerobic bacterium frequently found in deep pockets, and its predominance in deep peri-implant locations can accelerate tissue loss.

In disagreement with previous studies, Tabanella et al. in 2009 they observed that $T$. forsythia was not only found in locations with peri-implant lesions but also in specific mucositis lesions. This same study observed that the $P$. intermedia species also participates in the development of mucositis, concluding that $T$. forsythia , Campylobacter species, $P$. micros and Fusobacterium species are the periodontopathogens most frequently found in peri-implantitis locations. However Agreggatibacter actinomycetemcomitans it was not located in any location, which suggests that these bacteria are significant indicators of peri-implantitis.

Previous studies using culture techniques have identified a predominance of the species $P$. gingivalis , $P$. intermedia (Leonhardt et al. In 2003, Mombelli et al. 1995) and $A$. actinomycetemcomitans , Escherichia coli and S. aureus (Leonhardt et al. in 2003) in sites with peri-implantitis.

\section{CONCLUSIONS}

After this extensive review of the literature, we can understand that there are similarities between the etiology and pathogenesis of periodontal disease and periimplantitis. 
Taking into account the limitations of some studies, we can say that there is sufficient evidence to affirm that factors such as: a previous history of periodontal disease, poor oral hygiene and tobacco appear to expose the patient to a greater risk for the development of peri-implantitis. However, we have limited evidence to confirm the association of alcohol and peri-implantitis.

The placement of implants in partially edentulous patients is a procedure that is currently very frequently found in the dental clinic. A clear association has been established between the presence of periodontal disease and the consequent development of peri-implantitis, showing that those patients with periodontal disease are exposed to a greater risk of developing peri-implant inflammatory lesions due to the presence of possible niches present in the residual periodontal pockets. that colonize the adjacent surfaces of the implants. Despite the established association, this does not contradict the placement of implants in this type of patients, since some studies indicate that subjects with a history of periodontal disease can maintain healthy peri-implant tissues.

On the other hand, some studies indicate that genetic variations such as polymorphisms are related to the presence of peri-implant disease, as well as a previous relationship with periodontal disease. Some authors even suggest that the IL-1RN gene polymorphism may represent a risk for peri-implantitis, although it does not seem to be entirely clear whether this risk factor is associated with the development of periimplantitis.

It is well known that the presence of poorly controlled diabetes in adult patients poses an increased risk of experiencing periodontitis and infections. In the same way, it seems logical that the same thing happens in patients with dental implants. However, there is some controversy in this regard, although most studies suggest that those diabetic patients with poor metabolic control have also shown a greater risk for the development and progression of peri-implant disease, so we must be cautious and pay great attention avoiding place implants in patients with poor metabolic control. Being so,the control of oral hygiene and the periodontal status of the patient should be monitored before and after implant placement in order to avoid or at least minimize the risk of developing peri-implantitis.

Despite the lack of clinical studies that support the idea that the absence of keratinized gingiva or its width significantly influence plaque control, bleeding index or probing depth, and is not considered a An essential requirement for the maintenance of gingival health, clinical experience shows us that the presence of an inserted keratinized gum band offers greater resistance, preventing or delaying the loss of seal around the implants and making it difficult for bacteria to infiltrate. 
Different implant designs and surfaces that favor plaque retention play an important role in influencing the adhesion potential of host cells and bacteria. Different data on the prevalence of peri-implant disease are shown, although moderately rough surfaces are recommended as they seem to improve bone response compared to other types of surfaces.

More longitudinal studies are needed to consider risk variables and the inflammatory process that affect peri-implant tissues.

THE AUTHORS DECLARE NO CONFLICTS OF INTEREST.

\section{REFERÊNCIAS}

1. Aalam AA, Nowzari H. Clinical evaluation of dental implants with surfaces roughened by anodic oxidation, dual acidetched implants, and machined implants. The International Journal of Oral and Maxillofacial Implants 2005; 20: 793-8.

2. Albrektsson T, Isidor F. Consensus report session IV. In: Lang NP, Karring T. Proceedings of the First European Workshop on Periodontology. 1994; 365-9.

3. Albrektsson T, Wennerberg A. Oral implant surfaces: part 2 - review focusing on clinical knowledge of different surfaces. The International Journal of Prosthodontics. 2004; 17: 544-64.

4. Alsaadi G, Quirynen M, Komárek A, van Steenberghe D. Impact of local and systemic factors on the incidence of oral implant failures, up to abutment connection. J Clin Periodontol. 2007; 34 (7) Jul: 610-7.

5. Attard NJ, Zarb GA. A study of dental implants in medically treated hypothyroid patients. Clinical Implant Dentistry and Related Research. 2002; 4: 220-31.

6. Axelsson P, Lindhe J. Effect of controlled oral hygiene procedures on caries and periodontal disease in adults. Results after 6 years. Journal of Clinical Periodontology. 1981; 8: 239-48.

7. Baelum V, Ellegaard B. Implant survival in periodontally compromised patients. Journal of Periodontology. 2004; 75: 1404-12.

8. Baig MR, Rajan M. Effects of smoking on the outcome of implant treatment: a literature 
review. Indian J Dent Res 2007; 18: 190-5.

9. Bain CA, MoyPK. The association between the failure of dental implants and cigarette smoking. Int J Oral Maxilofac Implants. 1993; 8: 609-15.

10. Bain CA. Smoking and implant failure-Benefits of smoking cessation protocol. Int J Oral Maxilofac Implants. 1996; 11: 756-9.

11. Bain CA, Weng D, Meltzer A, Kholes SS, Stach RM. A metaanalysis evaluating the risk for implant failure in patients who smoke. Compend. 2002; 23: 695-706.

12. Berglundh T, Persson L, Klinge B. A systematic review of the incidence of biological and technical complications in implant dentistry reported in prospective longitudinal studies of at least 5 years. Journal of Clinical Periodontology. 2002; 29: 197-212.

13. Bergstrom J. Cigarette smoking as a risk factor in chronic periodontal disease. Community Dentistry and Oral Epidemiology. 1989; 17: 245-7.

14. Calistro, Lucas Cesar, et al. "Peri-implantite e mucosite peri-implantar. Fatores de risco, diagnóstico e tratamento." Brazilian Journal of Implantology and Health Sciences 2.3 (2020): 64-83.

15. Clares, Mario Dormani, and Sarmento George Scilio. "Tratamento clínico da periimplantite com manutenção do tecido de granulação." Brazilian Journal of Implantology and Health Sciences 1.7 (2019): 192-206.

16. De Boever AL, De Boever JA. Early colonization of non-submerged dental implants in patients with a history of advanced aggressive periodontitis. Clinical Oral Implants Research. 2006; 17: 8-17.

17. Deluca, Habsha E, Zarb GA. ie effect of smoking on osseointegrated dental implants. Part I: Implant survival. Int J Prosthodont 2006; 19: 491-8.

18. Ellegaard B, Baelum V, Karring T. Implant therapy in periodontally compromised patients. Clinical Oral Implants Research. 1997; 8: 180-8.

19. Emrani J, Chee W, Slots J. Bacterial colonization of oral implants from nondental sources. Clin Implant Dent Relat Res. 2009 Jun; 11 (2): 106-12.

20. Esposito M, Hirsch JM, Leholm U, Thosen P. Biological factors contributing to failures of osteointegrated oral implants. (II) Etiopathogenesis. Eur J Oral Sci. 1998; 106: 721-64.

21. Feloutzis A, Lang NP, Tonetti MS, Bürgin W, Brägger, U, Buser, D, Duff GW, Kornman, KS. IL-1 genepolymorphism and smoking as risk factors for peri-implant bone loss in a well-maintained population. Clinical Oral Implants Research. 2003; 14: 10-7.

22. Ferreira S, Silva G, Cortelli J, Costa J, Costa F. Prevalence and risk variables for periimplant disease in Brazilian subjects. Journal of Clinical Periodontology. 2006; 33: 929- 
35.

23. Fiorellini J, Nevins $M$. Dental implant considerations in the diabetic patient. Periodontology. 2000; 23: 73-7.

24. Fürst MM, Salvi GE, Lang NP, Persson GR. Bacterial colonization immediately after installation on oral titanium implants. Clin Oral Implants Res. 2007; 18: 501-8.

25. Galindo-Moreno P, Fauri M, Ávila-Ortiz G. Impact of smoking on marginal bone loss: A prospective study. Clin Oral Implants Res. 2005; 16: 579-86.

26. García-Calderón M, Cabezas Talavero J, Gallego Romero D, Torres Lagares D. Av Periodon Implantol 2004; 16 (1): 9-18.

27. Grössner-Schreiber B, Gripentrog M, Haustein I, et al. Plaque formation on surfacemodified dental implants. An in Vitro study. Clin Oral Implants Res. 2001; 12: 543-51.

28. Gruica B, Wang HY, Lang NP, Buser, D. Impact of IL-1 genotype and smoking status on the prognosis of osseointegrated implants. Clinical Oral Implants Research. 2004; 15 : 393-400.

29. Heitz-Mayfield LJ. Disease progression: identification of high-risk groups and individuals for periodontitis. J Clin Periodontol 2005; 32 (Suppl 6): 196-209.

30. Heitz-Mayfield LJA. Peri-implant diseases: diagnosis and risk indicators. J Clin Periodontol. 2008; 35 (Suppl. 8): 292-304.

31. Jansson H, Hamberg K, De Bruyn H, Brattha G. Clinical consequences of IL-1 genotype on early implant failures inpatients under periodontal maintenance. Clinical Implant Dentistry Related Research. 2005; 1: 51-9.

32. Karoussis IK, Kotsovilis S, Fourmousis, I. A comprehensive and critical review of dental implant prognosis in periodontally compromised partially edentulous patients. Clinical Oral Implants Research. 2007; 18: 669-79. [

33. Karoussis IK, Müller, S, Salvi G, Heitz-Mayfield LJA, Brägger U, Lang NP. Association between periodontal and peri-implant conditions: a 10-year prospective study. Clinical Oral Implants Research. 2004; 15: 1-7.

34. Klokkevold PR, Han TJ. How do smoking, diabetes, and periodontitis affect outcomes of implant treatment? Int J Oral Maxillofac Implants. 2007; 22 (Suppl): 173-20.

35. Kozlovsky A, Tal H, Laufer BZ, Leshem R, Rohrer MD, Weinreb M, Artzi Z. Impact of implant overloading on the peri-implant bone in inflamed and non-inflamed periimplant mucosa. Clin. Oral Impl. Res. 2007; 18: 601-10.

36. Lachmann S, Kimmerle-Muller E, Axmann D, Scheideler L, Weber H, Haas R. Associations between peri-implant crevicular fluid volume, concentrations of crevicular inflammatory 
mediators, and composite IL-1A-889 and IL-1B 13954 genotype . A cross-sectional study on implant recall patients with and without clinical signs of peri-implantitis. Clinical Oral Implants Research. 2007; 18: 212-23.

37. Llanos, Alexandre Hugo, et al. "Impacto da periodontite agressiva e da periodontite crônica na qualidade de vida relacionada à saúde bucal." Brazilian Journal of Implantology and Health Sciences ISSN 2.8 (2020): 37-49.

38. Leonhardt A, et al. Five-year clinical, microbiological, and radiological outcome following treatment of peri-implatitis in man. J Periodontol 2003; 74: 1415-22.

39. Leonhardt A, Dahlén G. Effect of titanium on selected oral bacterial species in Vitro. Eur J Oral Sci. 1995; 103: 382-7.

40. Leonhardt A, Olsson J, Dahlén G. Bacterial colonization on titanium, hydroxyapatite, and amalgam surfaces in vivo. J Dent Res. 1995; 74: 1607-12.

41. Lindquist LW, Carrlsson GE, Jemt T. A prospective 15-years follow up study of mandibular fixed prostheses supported by osseointegrated implants. Clin Oral Implants Res. 1996; 7: 329-36.

42. Melo, Antônio Renato, Carlos Eduardo Vieira Gomes, and Fabio Alexandre Melo Campos. "Relação entre diabetes mellitus e o processo de osteointegração de implantes dentários." Brazilian Journal of Implantology and Health Sciences 1.5 (2019): 101-118.

43. Mundt T, Marck F, Schwahn C, Biffar R. Private practice results of screw-type tepered implants: Survival and evaluation risk factors. Int J Oral Maxilofac Implants. 2006; 21: 607-14.

44. Ong CTT, Ivanovski S, Needleman IG, Retzepi M, Moles DR, Tonetti MS, Donos N. Systematic review of implant outcomes in treated periodontitis subjects. J Clin Periodontol. 2008; 35: 438-62.

45. Quirynen M, Abarca M, Van Assche N, Nevins M, van Steenberghe D. Impact of supportive periodontal therapy and implant surface roughness on implant outcome in patients with a history of periodontitis. Journal of Clinical Periodontology. 2007; 34: 80515.

46. Quirynen M, Bollen CM, Eysssen H, van Steenberghe D. Microbial penetration along the implant components of the Bränemark system. An in vivo study. Clin Oral Implants Res. 1994; 5: 239-44.

47. Quirynen M, De Soete M, Van Steenberghe D. Infectious risks for oral implants: a review of the literature. Clinical Oral Implants Research. 2002; 13: 1-19.

48. Paraguassu, Éber Coelho, et al. "Implant installation in patients with periodontal disease 
history." Research, Society and Development 9.2 (2020): e39922009-e39922009.

49. Renvert S, Persson GR. Periodontitis as a potential risk factor for peri-implantitis. J Clin Periodontol. 2009; 36 (Suppl. 10): 9-14.

50. Rimondini L, Farè S, Brambilla E, Felloni A, Consonni C, Brossa F, Carrassi A. The effect of surface roughness on early in vivo plaque colonization on titanium. J Periodontol. 1997; 68: 556-62.

51. Roos-Jansa ${ }^{\circ}$ ker AM, Renvert $\mathrm{H}$, Lindahl Ch, Renvert S. Nine-to fourteen-year followup of implant treatment. Part III: factors associated with peri-implant lesions. J Clin Periodontol. 2006; 33: 296-301.

52. Rosan B, Lamont RJ. Dental plaque formation. Microbes Infection. 2000; 2: 1599-607.

53. Rutar A, Lang N, Buser D, Burgin W, Mombelli A. Retrospective assessment of clinical and microbiological factors affecting peri-implant tissue conditions. Clin Oral Implant Res. 2001; 12: 189-95.

54. Salvi GE, Fürst MM, Lang NP, Persson GR. One-year bacterial colonization patterns of Staphylococcus aureus and other bacteria at implants and adjacent teeth. Clin. Oral Impl. Res. 2008; 19: 242-8.

55. Sánchez-Pérez A, Moya-Villaescusa MJ, Caffesse RG. (2007) Tobacco as a risk factor for survival of dental implants. J Periodontol. 2007 Feb; 78 (2): 351-9.

56. Scarano A, Piattelli M, Vrespa G, Caputi S, Piattelli A. Bacterial adhesion on titanium nitride-coated and uncoated implants: An in vivo human study. J Oral Implantol. 2003; 29: 80-5.

57. Schwartz-Arad, Samet N, Mamlider A. Smoking and complications of endosseous dental implants. J Periodontol. 2002; 73: 153-7.

58. Serino G, Ström C. Peri-implantitis in partially edentulous patients: association with inadequate plaque control. Clin Oral Impl Res. 2009; 20: 169-74.

59. Shwartz-Arad D, Samet N, Samet N, Mamlider A. Smoking and complications of endosseous dental implants. J Periodontol. 2002; 73: 152-7.

60. Socransky SS, Haffajee AD. Microbial periodontal ecology. Periodontology 2000. 2005; 38: $135-87$.

61. Subramani K, Jung RE, Molenberg A, Hammerle $\mathrm{CH}$. Biofilm on dental implants: a review of the literature. Int J Oral Maxillofac Implants. 2009 Jul-Aug; 24 (4): 616-26.

62. Tolstunov L. Implant zones of the jaws: implant location and related success rate. Journal of Oral Implantology. 2007; 33: 211-20. 
63. van Winkelhoff AJ, Goene RJ, Benschop C, Folmer T. Early colonization of dental implants by putative periodontal pathogens in partially edentulous patients. Clinical Oral Implants Research. 2000; 11: 511-20.

64. Warrer K, Buser D, Lang NP, Karring T. Plaque-induced peri-implantitis in the presence or absence of keratinized mucosa. An experimental study in monkeys. Clin Oral Implants Res. 1995; 6: 131-8.

65. Wennstrom Jl, Bengazi F, Lekholm U. The influence of the masticatory mucosa on the peri-implant soft tissue condition. Clin Oral Implants Res. 1994; 5: 1-8.

66. Westfelt E, Rylander H, Blohne G, Joanasson P, Lindhe J. The effect of periodontal therapy in diabetes. Journal of Clinical Periodontology. 1996; 23: 92-100.

67. Zitzmann NU, Berglundh T. Definition and prevalence of peri-implant disease. Journal of Clinical Periodontology 2008; 35: 286-91.

68. Weyant RJ, Burt BA. An assessment of survival rates and within patient clustering of failures for endosseous oral implants. J Dent Res. 1993; 72 (1): 2-8.

69. Weyant RJ. Characteristics associated with the loss and periimplant tissue health of endosseous dental implants. Int J Oral and Maxillofac Implants. 1994; 9 (1): 95-102.

70. Wu-Yuan CD, Eganhouse KJ, Keller JC, Walters KS. Oral bacterial attachment to titanium surfaces: A scanning electron microscopy study. J Oral Implantol. 1995; 21: 207-13. 